\title{
The Particularity of Aesthetic Education Practice in Higher Education Stage
}

\author{
Du Ren ${ }^{1}$ \\ ${ }^{1}$ School of Humanities and Social Sciences, Beihang University, Beijing 100191, China \\ dora2014@163.com
}

\begin{abstract}
The publication of the opinions on Comprehensively Strengthening and improving the aesthetic education in schools in the new era has promoted the implementation of aesthetic education in China in the new era. Schools at various stages have different aesthetic education practice methods. The higher education stage is a special stage, connecting the basic education stage and the future socialization stage. The age characteristics of the educated, the learning methods different from the basic education stage and the task of talent training in universities all require the aesthetic education practice of colleges and universities to have their own particularity. Therefore, when carrying out the practice of aesthetic education, colleges and universities should make corresponding countermeasures according to the particularity of various elements, and adjust measures to local conditions, so as to realize the cultivation of talents and the perfection of aesthetic education.
\end{abstract}

Keywords: Particularity, Aesthetic education, Higher Education

\section{AESTHETIC EDUCATION IN HIGHER EDUCATION STAGE IS THE TRANSITION BETWEEN SCHOOL AESTHETIC EDUCATION AND SOCIAL AESTHETIC EDUCATION}

In October 2020, the general office of the CPC Central Committee and the general office of the State Council issued the opinions on Comprehensively Strengthening and improving school aesthetic education in the new era. It is pointed out in the opinion that aesthetic education is "an education that enriches imagination and cultivates innovative consciousness, which can improve aesthetic quality, cultivate sentiment, warm heart and stimulate innovation and creativity" [1]. Whether from the perspective of mental health and personality improvement, or from the needs of improving learning ability and comprehensive quality, aesthetic education is of great help to students. Mr. Cai Yuanpei mentioned in his "methods for the implementation of aesthetic education" that aesthetic education, as an important part of education, is the same as moral education, physical education and intellectual education, it can also be divided into family aesthetic education, school aesthetic education and social aesthetic education [2]. Among them, family aesthetic education is mainly aimed at children before entering school, while social aesthetic education is more inclined to students who are not in school (such as holidays) and those who have left school. Therefore, aesthetic education should be a lifelong education [3].

In the scope of school aesthetic education, school is naturally the subject of responsibility. Colleges and universities in the stage of higher education not only undertake the basic education, but also pave the way to enter the society. It is an important period for students to realize spiritual independence and self discovery. Therefore, the aesthetic education in higher education stage naturally has the nature and characteristics different from that in the basic education stage. As Cai Yuanpei mentioned: "kindergarten is a transitional stage between family aesthetic education and school aesthetic education [4]."Colleges and universities can also be regarded as the transitional stage between school aesthetic education and social aesthetic education.This means that colleges and universities have a dual identity orientation in carrying out aesthetic education. They have not only the tasks and responsibilities of school aesthetic education, but also provide social aesthetic education platforms and channels for students. They should not only teach people "fish", but also how to get "fish", so that students can accept aesthetic education passively, To actively move towards aesthetic education, pursue aesthetic education, consciously discover beauty in the future life, feel beauty, 
improve aesthetic literacy, sublimate spiritual realm, truly maximize the effectiveness of aesthetic education, lifelong, and play the role of aesthetic education as a bridge between the phenomenon world and the real world to promote the personality completion of the educated [5].

\section{RICH PRACTICE PATHS OF AESTHETIC EDUCATION IN COLLEGES AND UNIVERSITIES}

Curriculum aesthetic education is an important path of school aesthetic education practice. The higher education stage is different from the basic education stage. Students have no collective pressure to enter higher education. Everyone seeks and develops their own development direction in their own specialty. It is mentioned in the opinions on Comprehensively Strengthening and improving the aesthetic education in schools in the new era," At the stage of higher education, public art courses with aesthetic and humanistic quality cultivation as the core, innovation ability cultivation as the focus, and the inheritance and development of Chinese excellent traditional culture and art classic education as the main content." Public course is a kind of course in Colleges and universities, which means that colleges and universities set up according to the general goal and general requirements of training various kinds of specialized talents, courses for students of all departments and majors [6]. Freshmen and sophomores are the intensive period for most colleges and universities to open public courses, and it is also a critical period for students to find themselves in the confusion and ignorance of their first enrollment. At present, with the deepening of "Internet + " in the field of education, the innovation and reform of public course teaching methods are constantly evolving, whether it is the mode of knowledge transfer or the interactive classroom between teachers and students, The practice of immersive experience enriches the teaching methods of public courses in Colleges and universities, which is conducive to stimulating students' interest in learning and changing the students' mentality of "signing in" in the past.This provides a good platform for the promotion of public aesthetic education. The public art courses mentioned in "opinions", It is not to let students achieve the level of art majors through class, but to appreciate art, learn art, cultivate sentiment, influence the mind, and then achieve spiritual growth.

In Aesthetics, Mr. Zhu Liyuan defines the connotation of aesthetic education as follows: "Aesthetic education takes art and various forms of beauty as concrete media means, displays the rich value of aesthetic objects through aesthetic activities, and directly acts on the emotional world of the recipients, thus subtly shaping and optimizing people's psychological structure and casting perfect humanity. An organized and purposeful directional education method to enhance the realm of life [7] ." Among them, the specific art and beauty forms are the media and means to carry out aesthetic education, and aesthetic activities are the learning process of learners, and they are finally taught in the emotional world of the educated, with the aim of subtly cultivating the soul and perfecting the personality. Therefore, we should not simply equate aesthetic education with "art education", but look at the teaching purpose behind public art courses. It is moistening things to affect people silently, changing people and achieving people. This has guided the teaching purpose of today's aesthetic education in colleges and universities, not to teach students to learn an instrument and master a painting skill, but to help students find themselves through spiritual growth and spiritual independence and truly realize "educating people" in the process of teaching. Therefore, the main focus of public courses of aesthetic education in higher education should be on teaching methods and models, rather than the final performance assessment. Make use of information-based teaching equipment and the appeal of new media, so that students can immerse themselves in the influence of beauty and gain growth in the classroom.

On the other hand, compared with the basic education stage, there is a broader world in aesthetic education practice in the higher education stage, that is, aesthetic education outside the classroom. Although in the stage of basic education, many schools enrich aesthetic education practice through lectures, group visits, theatrical performances and other forms, However, due to the pressure of classroom teaching and entrance examination, the limitation of students' age and experience, parents' consideration of safety and other factors, curriculum aesthetic education has always been the main way to practice aesthetic education in basic education stage. But at the stage of higher education, the educated are usually adults or about to become adults, and they are relatively mature in both thinking ability and behavior ability. At the same time, colleges and universities have rich students' social practice experience, which is more perfect than primary and secondary schools in terms of providing resources and platforms, and ensuring safety and activities. This is the place where colleges and universities can play their unique aesthetic education functions. As an important place for students to further socialize, colleges and universities can provide sufficient academic resources, practical opportunities and communication platforms. Whether it is to invite experts and artists related to aesthetic education to give lectures in combination with the classroom, or to hold art exhibitions through the art museum on campus, or to organize regular activities by school associations, organize students' social practice to carry out interdisciplinary exchanges and cooperation, and go to cultural bases for investigation and research ... All these are aesthetic education resources provided by colleges and universities for students in school.This kind of 
experience will inspire students' inner agitation and emotion. The aesthetic feeling, immersion and experience they experience in the process of personal practice are far from being realized in class. This also paves the way for students to take the initiative to accept the psychological needs of social aesthetic education after leaving colleges and universities in the future, paving the way for educating people and lifelong aesthetic education for adults. Maybe one day in the future, when the educated experienced the vicissitudes and frustrations of life, they can still remember the frustrations of the characters in the drama festival many years ago, resonate and inspire themselves, and they will still use the "hard work and hard work, let the east, west, north and south wind" heard in class to motivate themselves to move forward. If the aesthetic education effect can be truly realized to this extent, then our education is the real "kindness".

\section{CONCLUSION}

To sum up, aesthetic education in higher education has a strong particularity compared with that in basic education. First of all, it is the particularity of the educated, which is basically a group of people who have just grown up. Their world outlook, outlook on life and values are in the initial stage, and at the same time they have certain speculative ability. They are the most vulnerable group of people, and at the age of being the easiest to be opinionated. For the aesthetic education of college students, we should follow the method of moistening things silently, provide them with sufficient platform and resources, and encourage and guide them to explore and find themselves. What schools and teachers should do is not to follow the script or impart knowledge, but to inspire students' abilities and move their hearts. The second is the particularity of the education stage. The stage of higher education is different from the stage of basic education. There is no pressure of collective college entrance examination, and everyone is looking for their own possibilities here. Therefore, many students will enter a lost period after coming to university. When infinite possibilities are in front of them, they suddenly don't know where to go. Once immersed in this confused state, it is easy to miss the most precious college time and lose many opportunities that could have been seized. Therefore, aesthetic education in higher education is not only a kind of curriculum education, but also a practical platform. Let students know themselves through full experience, grasp themselves, and find a way that they really like and suit. Third, it is the particularity of colleges and universities. University is a school that implements higher education. Karl Theodor Jaspers believes that "university education is a subtle process, aiming at obtaining a far-reaching freedom [8]". The educational model of colleges and universities is quite different from that of primary and secondary schools. With the development of modern higher education, colleges and universities are no longer a closed and unknown peach blossom source, but an organization closely related to the development of society, culture and country, and a bridge for students to connect from ivory tower to society. Students are truly adults here, achieving spiritual independence and personality completion. Mr. Qian Weichang said this to university education: "I always think that the students trained in our university should first be a comprehensive person, a patriot, a dialectical materialist, a person with cultural and artistic accomplishment, noble moral quality and beautiful soul; Secondly, he is a person with disciplines and professional knowledge. A future engineer and expert. This purpose of university education determines the important position of humanistic education in university education. Because people's spirit and character can't be completely completed only by knowledge-based professional education ... Cultivating' comprehensive' people should attract the attention of university educators [9]". University is the place to train talents. Talent training refers not only to the teaching of professional knowledge, but also to create a person with firm belief, perfect personality and beautiful soul from all aspects. This is the original intention and return of education. As an important element of humanistic education, aesthetic education aims to cultivate such talents. Therefore, aesthetic education at the stage of higher education is also entrusted with the ideals and goals of universities, which are different from those of primary and secondary schools.

There is no doubt about the importance of aesthetic education, which, together with morality, intelligence, physical education and labor, constitutes an important part of education in China. They are independent of each other and penetrate each other, which is a dialectical relationship that promotes each other. The uniqueness of aesthetic education lies in arousing people's various psychological abilities and making them move harmoniously by directly infecting people's inner emotions.So as to subtly realize the shaping of people and continuously improve people's spiritual realm [10]. Aesthetic education in higher education is different from that in basic education because of its time, subject and place, and bears the transitional responsibility from school aesthetic education to social aesthetic education. Therefore, we should pay more attention to the promotion and construction of aesthetic education theory and practice in colleges and universities, and provide assistance for cultivating high-quality talents with both ability and political integrity.

\section{REFERENCES}

[1] Eneral Office of the CPC Central Committee and General Office of the State Council: "Opinions on Comprehensively Strengthening and Improving 
Aesthetic Education in Schools in the New Era", October 15, 2020

[2] Cai Yuanpei: Selected Works of Cai Yuanpei's Aesthetics [M],1983, Beijing: Peking University Press

[3] Be the same as the above

[4] Be the same as the above

[5] Be the same as the above

[6] Committee for compiling the Dictionary of Education. Dictionary of Education (Volume 3)[M]. Shanghai: Shanghai Education Press

[7] Zhu Liyuan: Aesthetics [M],2006, Beijing: Higher Education Press

[8] IELTS Bells: The Idea of University [M],2007, Shanghai: Shanghai People's Publishing House

[9] Qian Weichang: Selected Works of Qian Weichang [M], Volume VI, 2012, Shanghai: Shanghai University Press

[10] Zhu Liyuan: Aesthetics [M],2006, Beijing: Higher Education Press 